\title{
Circo nas aulas de Educação Física: para além do domínio motor
}

\section{RESUMO}

O presente artigo relata a prática pedagógica de docentes de Educação Física Escolar que desenvolveram dois projetos relacionados ao circo, sendo um com discentes do Ensino Fundamental e, outro, com os do Ensino Médio. Objetiva-se, inicialmente, discorrer sobre a importância do compromisso ético-político-pedagógico dos professores frente às disparidades sociais, a fim de estabelecer uma ação didática situada com vistas à emancipação coletiva, na acepção freireana. Em seguida, apresentam-se as potencialidades artísticas, afetivas, estéticas, críticas e socioculturais da tematização do circo nas aulas de Educação Física através do relato dos projetos "O circo chegou - o fazer coletivo das acrobacias" e "Circo: entre o espetáculo e o cotidiano". Os resultados evidenciam um rompimento com a visão tecnicista e projetam a potencialidade de tematizar o circo na educação básica como forma de possibilitar trocas humanizadoras provenientes de relações que se constituem a partir de um diálogo com o outro, com o mundo.

PALAVRAS-CHAVE: Circo; Ensino fundamental; Ensino médio; Educação física; Leituras de mundo

\section{Fernando Dias de Oliveira}

Doutorando em Educação e Sociedade Universidade de Barcelona, Faculdade de Educação, Barcelona, Catalunha, Espanha. fernandodias_oliveira@hotmail.com

(1) https://orcid.org/0000-0002-7819-0778

\section{Diogo Inacio Dias}

Mestrando em Educação Universidade Federal de São Carlos, Departamento de Ciências Humanas e Educação, Sorocaba, Brasil. diogo.inacio.dias@gmail.com

https://orcid.org/0000-0003-3205-0048

Luís Bruno de Godoy

Mestre em Ciências Humanas e Sociais Aplicadas

Universidade Estadual de Campinas Unicamp, Faculdade de Educação Física, Limeira-SP, Brasil. godoy.luisb@gmail.com

http://orcid.org/0000-0003-0857-9937

Rogério Zaim-de-Melo Doutor em Ciências Humanas e Educação Universidade Federal do Mato Grosso do Sul, CPAN, Corumbá-MS, Brasil. rogeriozmelo@gmail.com http://orcid.org/0000-0002-0365-6000 


\title{
Circus in Physical Education classes: beyond the motor domain
}

\begin{abstract}
This article reports the pedagogical practice of Physical Education teachers who developed two projects related to the circus, one with elementary school students and the other with high school students. The objective is, initially, to discuss the importance of the ethical-political-pedagogical commitment of teachers in face of social disparities, in order to establish a didactic action situated with a view to collective emancipation, in the Freirean perspective. Then, the artistic, affective, aesthetic, critical and sociocultural potentials of the circus theme in Physical Education classes are presented through the report of the projects "The circus has arrived - the collective doing of acrobatics" and "Circus: between the spectacle and the everyday". The results show a break with the technicist view and project the potential to thematize the circus in basic education to enable humanizing exchanges arising from relationships that are constituted from a dialogue with the other, with the world.
\end{abstract}

KEYWORDS: Circus; Elementary school; High school; Physical education; World readings

\section{Circo en las clases de Educación Física: más allá del dominio motor}

\section{RESUMEN}

Este artículo relata la práctica pedagógica de docentes de Educación Física que desarrollaron dos proyectos relacionados con el circo, uno con el alumnado de la Educación Primaria y otro de la Educación Secundaria. Inicialmente se buscó discutir la importancia del compromiso ético-políticopedagógico de los docentes frente a las desigualdades sociales, para establecer una acción didáctica situada que posibilite la emancipación colectiva, en la perspectiva freireana. A continuación, se presentan las potencialidades artísticas, afectivas, estéticas, críticas y socioculturales de abordar el circo en las clases de Educación Física, a través del relato de los proyectos "El circo llegó - la realización colectiva de acrobacias" y "Circo: entre el espectáculo y la vida cotidiana". Los resultados muestran una ruptura con la visión tecnicista y proyectan la potencialidad de tematizar el circo en la educación básica para posibilitar intercambios humanizadores que surgen de relaciones que se constituyen a partir del diálogo con el otro, con el mundo.

PALABRAS-CLAVE: Circo; Educación primaria; Educación secundaria; Educación física; Lecturas del mundo 


\section{INTRODUÇÃO}

Nos últimos anos, cresceram no Brasil as produções que relatam a presença do circo em diversos espaços, tais como academias, projetos sociais e, principalmente, na escola (BORTOLETO; MACHADO, 2003; ONTAÑÓN, 2016; ZAIM-DE-MELO et al., 2020), quer seja em projetos interdisciplinares, nas aulas de Arte e, sobretudo, nas aulas de Educação Física. Segundo Ribeiro et al. (2021, p. 247), com as atividades circenses, temos a "possibilidade de uma educação corporal artística e consequentemente estética”, ultrapassando a perspectiva motora.

Nesse sentido, nos centramos em refletir sobre os caminhos formativos da Educação Física na educação básica que estejam relacionados ao circo com vistas a possibilitar novas "leituras de mundo" (FREIRE, 1992) aos alunos e alunas.

Iniciamos situando e discutindo o cenário educacional brasileiro e os desafios aos quais os docentes de Educação Física Escolar estão submetidos, ressaltando a importância do compromisso ético-político-pedagógico desses profissionais em possibilitar a construção de uma sociedade mais equânime.

Em um segundo momento, exploramos o potencial artístico, afetivo, estético, crítico e sociocultural da tematização do circo na educação básica e seguimos para a apresentação de dois projetos: "O circo chegou - o fazer coletivo das acrobacias" realizado com discentes do Ensino Fundamental e "Circo: entre o espetáculo e o cotidiano" desenvolvido com discentes do Ensino Médio.

\section{Os Ensinos Fundamental e Médio em evidência: a importância do compromisso ético-político-pedagógico dos docentes frente às disparidades sociais}

O sistema educacional brasileiro vem passando, nas últimas décadas, por importantes transformações no que se refere à expansão e à universalização do acesso à educação básica. A trajetória histórica desse nível de ensino nos mostra que as classes sociais menos favorecidas sempre tiveram grandes dificuldades de cursá-lo (GENTILI, 1995; SAVIANI, 2007; OLIVEIRA; MALDONADO, 2018), de modo que entre os desafios atuais destacam-se a necessidade de assegurar ao alunado a equidade quanto às condições de permanência na escola e de propor um currículo que possibilite uma conexão entre o novo perfil de jovens que constituem hoje o espaço escolar e os desafios da sociedade contemporânea (GATTI et al., 2019). 
Ao analisarmos as Sinopses Estatísticas da Educação Básica do ano de 2019, é possível constatar a complexidade do sistema educacional brasileiro, visto que, no referido ano, havia um total de 26,9 milhões de discentes matriculados no Ensino Fundamental e outros 7,4 milhões matriculados no ensino médio (INEP, 2019). Ainda que na virada para o século XXI o Brasil tenha conseguido lograr que praticamente todos os jovens de 7 a 14 anos estivessem matriculados no Ensino Fundamental, o cenário para o Ensino Médio ainda é bastante dramático (GATTI et al., 2019), uma vez que 1,2 milhão de adolescentes entre 15 e 17 anos estão totalmente fora da escola (INEP, 2019).

Quando aprofundamos a análise de dados do referido documento quanto à permanência na escola ao longo dos anos, nota-se que aproximadamente $30 \%$ dos adolescentes de até 18 anos não concluem o Ensino Médio ${ }^{1}$, frente a cerca de $18 \%$ no ciclo anterior.

[...] sendo o Brasil ainda marcado por profundas inequidades do ponto de vista da distribuição de renda e dos benefícios sociais, não é de surpreender que persistam fortes desigualdades no que se refere ao acesso à educação, à capacidade de prosseguir nos estudos e à qualidade da educação recebida. Elas passam pela grande clivagem da origem socioeconômica da população, pelo seu pertencimento de gênero e étnico-racial, sendo os homens mais pobres e menos brancos os mais prejudicados (GATTI et al., 2019, p. 100).

Seguindo em um diálogo com essa obra encomendada pela Organização das Nações Unidas para a Educação, a Ciência e a Cultura (UNESCO) e que foi produzida pelas pesquisadoras brasileiras supracitadas, observa-se que há um conjunto de fragilidades intrínsecas ao sistema educacional brasileiro provocadas, especialmente, pelo baixo investimento em aspectos humanos e materiais, além da descontinuidade de algumas políticas públicas. Isso somado às dimensões populacional e territorial faz com que existam características disfuncionais nos currículos, problemas estruturais nas escolas, desvalorização do corpo docente, irregularidade no fluxo de matrículas e que parte da população brasileira ainda não consiga concluir a educação básica ou não o faça no tempo esperado.

A educação física, como componente curricular obrigatório da educação básica, também está inserida nesse contexto em que urge dialogar e dar respostas às demandas de uma sociedade desigual (OLIVEIRA; PESCE, 2020). Nos inspiramos em Freire (1967) e em Freire e Shor (1986) para pensar uma educação que contribua para a emancipação dos grupos sociais menos favorecidos. O empoderamento, na acepção freireana, concentra-se em uma dimensão coletiva e perpassa, entre

\footnotetext{
${ }^{1}$ Sendo consideradas as somas das taxas de abandono, evasão e reprovação.
} 
outros aspectos, a transposição da consciência ingênua para a crítica, possibilitando, assim, a transformação das relações sociais de poder.

Devemos ser muito, mas muito críticos cada vez que falarmos na educação emancipadora, educação libertadora ou liberadora. Devemos sempre repetir que, com estas expressões, não queremos dizer que, na intimidade de um seminário, estamos transformando as estruturas da sociedade. Isto é, a educação libertadora é uma das coisas que devemos fazer, junto com outras coisas, para transformar a realidade. Devemos evitar que nos interpretem como se estivéssemos pensando que deveríamos primeiro educar as pessoas para serem livres, para depois podermos transformar a realidade. Não. Devemos, o quanto possível, fazer as duas coisas simultaneamente. Por isso, devemos estar engajados na ação política contra o racismo, contra o sexismo, contra o capitalismo, e contra as estruturas desumanas de produção (FREIRE; SHOR, 1986, p. 199).

Em consonância ao exposto, a educação física é uma das múltiplas formas de atuar na transformação do cenário anteriormente evidenciado. Ao discorrer sobre um conjunto de experiências pedagógicas no campo da educação física escolar, Neira (2020) salienta a importância da dimensão ético-política da prática pedagógica:

A seleção das práticas corporais que serão tematizadas e os encaminhamentos pedagógicos dão-se sob influência de princípios ético-políticos: reconhecimento da cultura corporal da comunidade, descolonização do currículo, justiça curricular, rejeição ao daltonismo cultural, favorecimento da enunciação dos saberes discentes e ancoragem social dos conhecimentos (NEIRA, 2020, p. 829).

Nós, como docentes e investigadores dessa área do conhecimento, acreditamos que, a partir dos saberes historicamente acumulados sobre as práticas corporais, é possível ao alunado realizar novas e diferentes leituras de mundo, atuando de maneira autônoma e crítica com vistas à emancipação coletiva, na perspectiva freireana.

\section{O circo como possibilidade}

Circo, arte circense, atividades circenses na escola. Na literatura, encontramos pesquisas em que essas três denominações são formas concorrentes. Neste texto, utilizaremos a denominação circo, para os projetos que foram desenvolvidos, pois o intuito principal foi ultrapassar a barreira mecanicista do movimento pelo movimento. Buscou-se compreender o circo e todos os sentidos e significados que ele carrega, para que, ao final, os alunos, além de terem experenciado uma prática corporal diferente em suas aulas de Educação Física, pudessem compreender os aspectos estéticos relacionados ao conceito de atividades circenses. 
Assim como Ribeiro et al. (2021), consideramos o circo como patrimônio cultural da humanidade e, por esta razão, já deveria estar na escola formal há bastante tempo. O que na prática não acontece. Nos últimos documentos nacionais que serviram de base para a educação no Brasil, os Parâmetros Curriculares Nacionais (PCNs) e a Base Nacional Comum Curricular (BNCC), há pouca ou quase nenhuma menção ao circo. Nos PCNs não há referência alguma, nem no documento de Arte, tampouco no de Educação Física. Já, na BNCC, há uma passagem na parte de Arte referindo-se à arte circense, enquanto a música, o teatro, a dança e as artes visuais são colocadas em destaque.

Uma das razões que podemos apontar para essa não apropriação do circo na escola deve-se, talvez, ao fato de que, com as atividades circenses que podem ser realizadas, a lógica da criança comportada é subvertida, anda-se sobre as mãos, rola-se no chão, correm-se riscos, mesmos que programados (SOARES, 2013), rompendo com os paradigmas da ideia de controle biopolíticosocial dos corpos amplamente debatidos por Foucault (1977).

Contrariando aos documentos oficiais e valendo-se da potencialidade educativa do circo, paulatinamente, o corpo docente de Educação Física - destacadamente - e de Arte vêm se apropriando dessa arte milenar. Zaim-de-Melo, Godoy e Bracialli (2020), visando conceber uma proposta para a inserção do palhaço nas aulas de Educação Física, realizaram um levantamento sobre publicações em periódicos avaliados pelo sistema Qualis Capes entre os anos de 2010 e 2019. Utilizando bases indexadoras (Lilacs, Scopus e SciELO) da ferramenta de pesquisa Scholar Google e do site do periódico "Educación Física y Deportes”, buscaram textos cujo escopo era a presença das atividades circenses na escola. Os termos utilizados para a busca foram "atividade(s) circense(s)" AND “Educação Física escolar", “arte(s) circense(s)" AND "Educação Física escolar" e "Circo" AND "Educação Física escolar" (ibidem). Foram encontrados 50 artigos que tratavam sobre o tema, com uma diversidade de práticas circenses, embasadas em taxonomias que foram desenvolvidas para orientar o planejamento de propostas pedagógicas (DUPRAT, PÉREZGALLARDO, 2010; BORTOLETO, 2017).

\section{O circo como potencialidade}

Tem ocorrido nos últimos anos, especialmente, uma fragilização das relações e trocas sociais. Antes mesmo do isolamento proveniente da pandemia de Covid-19, já enfrentávamos distanciamentos decorrentes da contemporaneidade, na maioria das vezes, atrelados ao crescimento 
das tecnologias digitais e a um medo recorrente do outro, justificado pela crescente desigualdade social e pelas políticas pró-armamentistas que surgem paralelas a políticas higienistas de Estado.

Junto a esses aspectos, discursos meritocráticos impulsionam uma excessiva necessidade de autoafirmação, que, por sua vez, reforça a individualidade e as desigualdades, preservando a estabilidade e as linhas territoriais a serem mantidas. Assim, o outro torna-se uma ameaça que deve ser evitada para que essas linhas hegemônicas possam ser sustentadas, e, todo aquele que, de alguma maneira, vier a desestabilizar tal linha será imediatamente visto como um intruso, um invasor, um estranho (BAUMAN, 1998; GODOY et al. 2020; 2021).

Assim, ao tratarmos da arte, considerando-se todas as suas formas de manifestação, também estamos nos referindo a aspectos humanos, de trocas provenientes de relações que se constituem com o outro, com o mundo (CARRASCO-SEGOVIA; HERNÁNDEZ-HERNÁNDEZ, 2020), uma abertura para além das linhas territoriais fronteiriças que sustentam os modelos a serem seguidos. A arte reconfigura o mundo à sua maneira, produz um espaço aberto, perene e em constante modificação justamente por estar atrelada à cultura e, se compreendemos que a cultura não é estática, facilmente entenderemos que a arte também não.

Em contrapartida, com base nos pensamentos de Deleuze e Guattari (2011), veremos que a arte se conserva, mas não uma conservação relativa à ordem da manutenção daquilo que está dado, a arte se conversa em si e para si, em um bloco de sensações criado por aquele que a compõe.

O que se conserva, a coisa ou a obra de arte, é um bloco de sensações, isto é, um composto de perceptos e afectos. [...] As sensações, perceptos e afectos, são seres que valem por si mesmos e excedem qualquer vivido. Existem na ausência do homem, podemos dizer, porque o homem, tal como ele é fixado na pedra, sobre a tela ou ao longo das palavras, é ele próprio um composto de perceptos e de afectos. A obra de arte é um ser de sensação, e nada mais: ela existe em si (DELEUZE; GUATTARI, 2011, p. 16).

$\mathrm{O}$ artista cria sua obra a partir de todos os perceptos e afectos ${ }^{2}$ que propiciam a instauração desse espaço-outro que se sustenta tempo-espacialmente conservando em si os blocos de sensação outrora criados pelo artista. Ou seja, a própria obra que, ao ser constituída pelo artista, passa a ser um ser de sensações independente do artista que a criou. E, é nesse ponto no qual reside uma das grandes potencialidades da arte e que perdura ao longo dos séculos. Segundo Gadamer (2015), a arte ganha um ser ao tornar-se uma experiência que transforma aquele que dela experimenta, no entanto, o que na arte fica e permanece não é subjetividade de quem a experimenta, mas, a própria

\footnotetext{
${ }^{2}$ Perceptos correspondem a um conjunto de sensações e percepções que vão além daquele que a sente. Afectos, por sua vez, são um conjunto de percepções e sensações que se tornaram independentes de quem as sente (PARNET, 2010).
} 
obra que se constituiu como um ser de sensações. A arte, assim como o jogo, tem uma natureza própria, independente dos jogadores que a jogam.

Nessa experiência do jogo presente na arte, os encontros não só se tornam possíveis, mas, intensificam-se, pois o artista, como obra viva, encontra-se com aquele que dele experimenta, é um duplo movimento, em que se afeta e se é afetado, simultaneamente, como apontado por Ferracini (2006), uma dupla seta de afetação, para fora e para dentro, na qual, para fora (afetar), o artista busca possibilidades para ampliar suas ações e lançá-las para fora: para o externo, para o outro; caso isso não ocorra, o espectador não receberá a ação ou não será afetado por ela. Já, a seta para dentro (ser afetado), é uma abertura do artista para aquilo que é externo, para um corpo em arte, poroso.

No entanto, antes de avançarmos, é necessário compreender o que aqui chamamos de experiência, entendendo que essa se relaciona às marcas deixadas no sujeito e não às informações adquiridas por ele, isso talvez seja o que diferencia a experiência da vivência. Experiência é aquilo que afeta, afetar no sentido de deixar marcas no sujeito, as quais geram deslocamentos, modificações microperceptíveis, aquilo que é experienciado intensamente (LARROSA, 2017). A experiência pressupõe encontro e, nesse encontro, o eu e o outro se colocam como sujeitos passíveis de afetar e de serem afetados (GODOY et al. 2020; 2021).

Dessa forma, na contemporaneidade, a arte, mais especificamente aquela que está em meio ao público, torna-se uma forma de resistir ao enrijecimento das relações. Nesse sentido, ganha relevo a arte circense como forma de gerar encontros. É por meio de seu jogo, desde o princípio, que o circo buscou seu público, estando em meio a ele, conectando-se e, tornando-se ele. Assim, a arte circense conforma uma possibilidade de reavivar o corpo contemporâneo - rendido aos ditames midiáticos e sociais, e convertido em um corpo ameno, criador de desencontros, protecionista, que se esquiva - e torná-lo novamente potente, que não só reage aos excessos de informações, mas que experiencia, afeta e é afetado, um corpo que joga com a incerteza e se reafirma frente à vida.

A partir dos antecedentes expostos, apoiamo-nos em Contreras (2016) para relatar duas experiências pedagógicas, sendo uma com alunos e alunas dos anos finais do Ensino Fundamental e outra do Ensino Médio. Conforme menciona o aludido autor, é por meio dos relatos de experiência que indagamos o vivido, buscando luz para perceber com mais amplitude a própria noção de experiência e nos orientar melhor no caminho da docência, gerando novos saberes pedagógicos.

\section{O circo chegou! Um projeto de trabalho de acrobacias com uma turma de $6^{\circ}$ ano \\ O projeto intitulado "O circo chegou - o fazer coletivo das acrobacias" foi desenvolvido} entre a última semana de fevereiro e as três primeiras de março do ano de 2020, no primeiro 
trimestre, ainda antes da triste e desoladora consolidação da pandemia de Covid-19, em uma escola particular da região metropolitana de São Paulo, com uma turma de 22 crianças de um $6^{\circ}$ ano do Ensino Fundamental II, ao longo de 8 aulas com duração de 50 minutos cada uma, tendo como docente à frente do processo, um dos autores deste artigo. O projeto teve como objetivo central a vivência da modalidade circense de acrobacia de solo atentando para os elementos colaborativos essenciais à prática, bem como os aspectos de segurança individual e coletiva e seguindo uma perspectiva multicultural e crítica (NEIRA, 2016; 2017).

Dentro do corpo das modalidade circenses, as acrobacias de solo coletivas parecem ser uma metáfora bastante interessante do fazer comunitário, traço marcante do circo itinerante brasileiro, como mostrado na obra de Bolognesi (2003) em que o autor apresenta relatos de sua pesquisa de campo acompanhando tradicionais famílias circenses brasileiras em seus respectivos circos, viajando pelo Brasil. Fica evidente, a partir do relato, que a afirmação de que o fazer circense é coletivo e coletivizado, sendo necessário, então, o envolvimento, a participação, a colaboração e criação de uma força coletiva de sustentação e manutenção do fazer circense itinerante. Algo semelhante pode ser observado no empenho e esforço dos alunos e das alunas ao serem desafiados a sustentarem-se uns aos outros na realização das acrobacias de solo, como veremos adiante.

Ancorado, então, em Bolognesi (2003) como elemento de suporte à tematização do circo do ponto de vista histórico, social, político e poético, e nas contribuições de Duprat e Bortoleto (2007), Bortoleto $(2008 ; 2010)$ no sentido de pensar e propor a pedagogia das atividades circenses, um caminho para o ensino do circo, de maneira sistematizada, prática e teoricamente, o projeto começou a ser gestado, no período de planejamento escolar, em janeiro. Ainda nesse processo gestacional, o trabalho de Larrosa (2002) foi alicerce para a compreensão do projeto como espaço de experiência, relação, atravessamento do sujeito pela própria experiência, fugindo dos caminhos curtos e superficiais, mas, por vezes sedutores, da experiência técnica, puramente sistemática, biológica e alienada, que robotiza o corpo e no interior dele não é mais visto como natural, pertencente a nós mesmos, mas como uma composição de outrem, que funciona a partir de mecanismos pré-determinados externamente, como também discute Novaes (2003).

Considerando-se os riscos dessa robotização e buscando construir o espaço da experiência crítica, política, social, humana - o projeto foi estruturado a partir de quatro eixos subsequentes: i) levantamento de conhecimento prévio e diagnóstico (uma aula); ii) tematização do circo e das acrobacias de solo (uma aula); iii) experimentação e criação de repertório (quatro aulas) e; iv) criação e apresentação de produtos coletivos (duas aulas). A seguir, descrevemos como o trabalho foi desenvolvido com as crianças em cada um desses eixos do projeto. 
A fase diagnóstica, da qual fazia parte o levantamento de conhecimento prévio acerca do que as crianças já conheciam sobre circo e acrobacias, ocorreu por meio de uma atividade disparadora. Logo após a realização da chamada, em consonância com essa etapa inicial da aula, foi apresentada aos discentes uma tirinha de "Suriá, a garota do circo", de autoria da quadrinista Laerte Coutinho (Figura 1).

Figura 1. - Suriá.

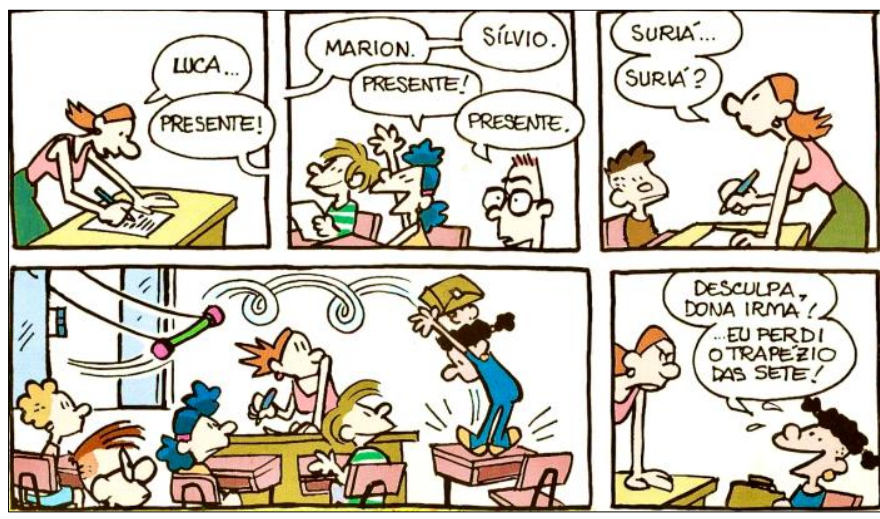

Fonte: Laerte (2000).

Em uma roda de conversa, a partir da análise tirinha, construímos coletivamente um mapa de vocabulário sobre os conceitos de "circo" e "acrobacia" com as crianças. Palavras como "lona", "picadeiro", "palhaço", "mágica", "pirâmides", "cambalhota", "parada de mão", "malabarismo", dentre outras, surgiram e foram o "chão no qual fixamos o morto"3 e as colunas de sustentação da nossa lona de conhecimentos ainda em início de construção. Além da criação desse mapa de vocabulário, também dedicamos um tempo da aula para andar pelo prédio da escola direcionando o nosso olhar para as formas arquitetônicas de sustentação dos telhados e paredes com ênfase nas relações angulares estabelecidas entre vigas e colunas de sustentação, para, na sequência, realizar uma atividade de pesquisa corporal na qual as crianças buscaram reproduzir, utilizando as articulações corporais mais diversificadas, essas relações arquitetônicas de sustentação observadas.

$\mathrm{Na}$ fase seguinte, de tematização do circo e das acrobacias de solo, trabalhamos de maneira híbrida, por meio de uma estratégia vinculada às práticas da sala de aula invertida (BERGMANN; SAMS, 2017). Na sala de aula virtual da turma, previamente ao encontro presencial, na plataforma Google for Education, o grupo teve acesso ao filme "O palhaço" de 2011, direção e roteiro de Selton Mello, a uma seleção de mais algumas tirinhas de "Suriá pré-selecionadas pelo professor, e de imagens retiradas do livro "Circo Nerino" (AVANZI; TAMAOKI, 2004). Essas referências foram disparadoras de temas como o processo histórico do circo itinerante, o cotidiano de uma

\footnotetext{
${ }^{3}$ Mecanismo enterrado em certa profundidade em terrenos arenosos ou pantanosos, ao qual se prendem cordas ou cabos de aço que que servirão de ponto de ancoragem dos mastros e ou mastaréus de sustentação da lona do circo.
} 
família circense e do universo artístico e estético do circo. Os alunos e as alunas deviam escolher livremente ao menos uma das referências disponibilizadas, apreciá-las e elaborar uma breve síntese a ser compartilhada com a sala nos 25 primeiros minutos da aula seguinte em uma roda de conversa mediada pelo professor e orientada por duas perguntas: i) O que é o circo itinerante?; ii) O que é uma acrobacia ${ }^{4}$ ? $\mathrm{Na}$ sequência dessa atividade, iniciamos o trabalho específico com as acrobacias realizando uma atividade prática de diferenciação das funções de portô e volante ${ }^{5}$, introduzindo ao grupo acrobacias de baixa complexidade nas quais o porto se coloca com as costas e parte do quadril apoiados no chão.

Nas quatro aulas seguintes, mergulhamos de cabeça na pesquisa, experimentação e prática de algumas figuras acrobáticas em duplas ou em grupos maiores. Essas quatro aulas tiveram como tema as seguintes figuras acrobáticas:

Aula 1: figuras acrobáticas com o portô de costas apoiadas no chão - cadeirinha de 2, 3, 4 pessoas e avião.

Aula 2: figuras acrobáticas com o portô em 6 apoios (joelhos e palmas das mãos no chão) pirâmide de 3 pessoas, volante sentado na região do quadril do portô, volante em pé nas costas do portô.

Aula 3: ampliação e aumento do grau de complexidade das figuras acrobáticas com o portô em 6 apoios - pirâmide de 6 pessoas.

Aula 4: figuras acrobáticas com portôs em 6 apoios e/ou com as costas no chão - proposta de combinação de algumas figuras acrobáticas experimentadas (pirâmide e cadeirinha, por exemplo).

O script da aula ${ }^{6}$ nesses 4 encontros foi construído sobre três momentos de prática: primeiramente, uma brincadeira ou jogo de aquecimento e preparação corporal para a aula, já direcionado para o tema de trabalho do dia. Na sequência, a parte central da aula: rotinas de exercícios acrobáticos coletivos, geralmente contendo situações problemas a serem resolvidas em pequenos grupos, ou ainda desafios a serem solucionados coletivamente a partir de referências em imagens esquemáticas, das figuras acrobáticas a serem trabalhadas naquela aula.

Depois de uma rápida reunião e discussão em grupo no sentido de traçar uma estratégia coletiva de realização do exercício ou de resolução da situação problema ou desafio, sempre compartilhada previamente com o professor, é que se iniciava o trabalho de teste, experimentação e colocação em prática do resultado desse levantamento coletivo de hipóteses. Ao final de cada aula,

${ }^{4}$ Aqui nos apoiamos em Bortoleto $(2008 ; 2010)$ a fim de caracterizar o que é acrobacia de solo.

5 Neste trabalho, utilizamos as definições de "portô" e "volantes" disponíveis em: http://circodata.com.br/index.php?c=glossario\& Acesso em: 01 set. 2021.

${ }^{6}$ Os planos de aula foram inspirados nas propostas de exercícios de Bortoleto $(2008 ; 2010)$. 
nos últimos 10 minutos, cada grupo de trabalho partilhava o resultado de seu processo investigativo com a sala, no sentido de expor seu processo de aprendizagem naquela aula, além de cada estudante ter a possibilidade de confrontar eventuais percalços do próprio grupo com os dos demais.

Por fim, nas últimas duas aulas do projeto, foi lançado ao grupo de alunos o desafio de criarem figuras acrobáticas coletivas utilizando os conhecimentos desenvolvidos nas semanas anteriores. Em grupos de 5 a 6 pessoas, os alunos e as alunas tiveram o tempo de uma aula para criar uma sequência de 3 figuras acrobáticas coletivas, utilizando o repertório construído ao longo do projeto. Essas três figuras deveriam ser registradas na forma de desenho esquemático em uma folha sulfite e apresentada ao professor até a metade do tempo dessa primeira aula, somente, então, os grupos partiram para o treino / ensaio dessa sequência de acrobacias.

Fig. 2 - Esquematização de figuras acrobáticas propostas por um grupo de alunos:
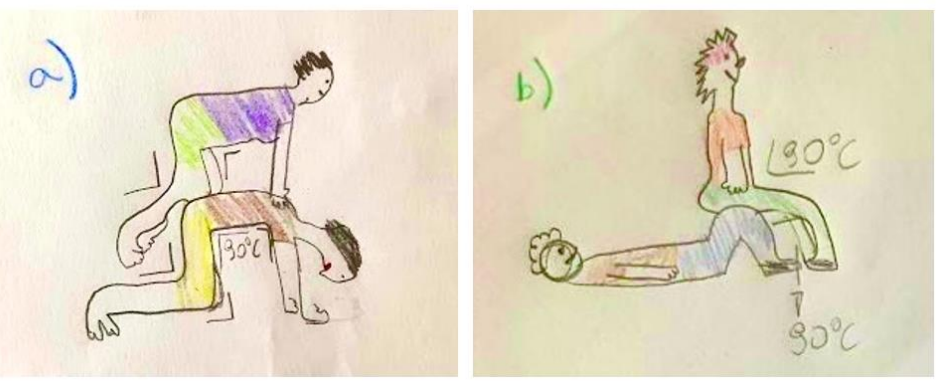

Fonte: Registro fotográfico dos autores.

Novamente utilizando a estratégia da sala de aula invertida, por meio de referências em vídeo de apresentações de números acrobáticos coletivos (dando preferência a vídeos oriundos de registros de artistas de circos itinerantes disponíveis no Youtube e previamente selecionados pelo docente) os grupos foram estimulados a pensar em uma temática que norteasse a apresentação, bem como em uma trilha sonora e em um figurino.

Já, na última aula do projeto, os grupos que assim desejaram, compareceram à aula com seus figurinos e trilhas sonoras para a apresentação de seu número de acrobacia para a sala. Os grupos tiveram 15 minutos para um último ensaio, para, então, realizarem a mostra do produto de seu processo.

Ao longo da realização do projeto, ficou evidente para o docente, a partir da observação do desempenho, envolvimento e evolução do grupo-classe, documentado com a utilização de recursos audiovisuais, bem como das produções (em aula ou do produto final), que foi possível atingir não somente os objetivos centrais delineados como também trilhar um caminho de construção coletiva em conformidade com a perspectiva crítica e multicultural (NEIRA, 2016; 2017), distanciando os 
discentes de uma prática meramente mecanicista e maquinificante (NOVAES, 2003) e aproximando-os da construção do saber da experiência a partir do que propõe Larrosa (2002).

\section{Situando o currículo de Educação Física no Ensino Médio: uma experiência com circo em uma escola pública.}

A proposta didática para as aulas de Educação Física no Ensino Médio pauta-se em uma perspectiva multicultural e crítica (APPLE, 1999; CANDAU, 2012; NEIRA, 2016; BONETTO; NEIRA, 2017; NEIRA, 2020) e busca possibilitar a formação para a diversidade, de modo a suscitar diferentes "leituras de mundo" (FREIRE, 1992) a partir de práticas corporais como danças, esportes, lutas, ginásticas, jogos, brincadeiras, entre outras.

Nesse sentido, os aspectos culturais, sociais, históricos e biológicos, além das significações sobre etnia, raça, gênero e classe social, formam parte das aulas desse componente curricular. Desse modo, alguns marcadores sociais são problematizados e continuamente relacionados com os saberes historicamente acumulados sobre as práticas corporais (OLIVEIRA; MALDONADO, 2018).

Uma característica constante dessas aulas de Educação Física escolar é que em nenhum momento há divisão por gênero. Essa composição de aula é realizada a partir do diálogo com os alunos e as alunas desde o início do ano letivo e vale para todos os momentos de aula e conteúdos abordados ao longo do ano. Um ponto de partida para essa decisão é a de possibilitar que o conjunto de discentes, ao longo do período formativo, possam reconhecer as diferenças existentes e respeitar o seu corpo e o do outro, de modo a reforçar e estimular uma atitude de respeito à diversidade esperada em outros ambientes sociais externos à escola.

Ao refletirem sobre o sucesso da utilização de situações lúdicas relacionadas ao circo na Educação Física Escolar, Melo, Bortoleto e Barragán (2021) evidenciam que na literatura há mais experiências relacionadas com o Ensino Fundamental, ao passo que são poucos os estudos que relatam experiências com discentes do Ensino Médio. Para esses autores, quando o circo é abordado na Educação Física no Ensino Médio, frequentemente as aulas ocorrem por meio da exploração livre de movimentos das atividades propostas.

O circo - ponto de partida para a escrita deste relato - é abordado como uma forma de realizar incursões a partir do aspecto lúdico e da experimentação de movimentos, mas com especial atenção à dimensão sociocultural dos sujeitos implicados. Realizadas essas considerações iniciais, seguimos para a descrição de um projeto desenvolvido em uma escola pública da cidade de São Paulo. 


\section{A vida por trás da lona: a formação crítica do alunado do Ensino Médio a partir da tematização do circo}

O circo nasceu com mundo
O mundo nasceu palhaço
É um barracão de lona
Erguido em cabos de aço
Saltador e trapezista
Frutos do mesmo baraço
Conheço o mundo do circo
Plateia uma ressalva eu faço
Artista família unida
No picadeiro da vida
Também tem o seu fracasso

Cada palhaço é uma história

Que eles traz no coração

Conta todas menos essa

No decorrer da função

Para mim em particular

Alguns faz revelação

Pois eu conheço um palhaço

Estimo como um irmão

Sua história me entristece

Só no picadeiro esquece

Pra sorrir a multidão

O mundo do circo, Teixeirinha.

O trecho da música em destaque foi uma das inspirações iniciais para dar sentido à tematização do circo junto aos estudantes do Ensino Médio. As considerações feitas na música escrita por Teixeirinha são um convite à reflexão, uma vez que, no decorrer das estrofes, o artista projeta tanto um aspecto lúdico do palhaço expresso na célebre frase "Hoje tem marmelada? Tem sim senhor!" quanto uma problematização social do cotidiano circense.

Essas reflexões culminaram na concepção do projeto intitulado "Circo: entre o espetáculo e o cotidiano", desenvolvido com duas turmas do $2^{\circ}$ ano do Ensino Médio de uma escola pública da região metropolitana da cidade de São Paulo durante o segundo bimestre de 2017, tendo como docente à frente do processo, um dos autores deste artigo. No total, 70 adolescentes (cerca de 35 alunos de cada turma) participaram das atividades que estiveram integradas à disciplina de Educação Física. Cabe ressaltar, que o tema circo estava previsto na proposta curricular da referida disciplina.

O projeto teve duração de quatro semanas e contou com duas aulas semanais seguidas de 45 minutos cada uma. Objetivou-se, inicialmente, que os alunos e as alunas refletissem sobre uma dimensão sociocultural mais ampla do cotidiano dos artistas de um circo itinerante para, então, explorar práticas corporais de algumas modalidades do circo. 
Na primeira semana, a música "O mundo do circo" do compositor Teixeirinha foi utilizada como forma de ilustrar o cenário que, muitas vezes, se descortina por trás da lona de circo. Após essa sensibilização inicial por meio da escuta atenta da música, instaurou-se uma roda de conversa sobre as representações que os alunos tinham sobre o circo e, em que medida, elas dialogavam com as representações veiculadas na música. Um aspecto interessante desse primeiro momento de diálogo é que muitos dos alunos e das alunas nunca haviam entrado em um picadeiro ou experienciado o circo, mas tinham referências de alguns personagens circenses, com destaque à figura do palhaço, por conta da veiculação de sua imagem nos meios de comunicação de massa.

Sequencialmente, os discentes assistiram a trechos do documentário "Vida de Circo 7" produzido pela TV da Universidade Federal do Paraná e que aborda o cotidiano de uma tradicional família de circenses de característica itinerante. Assim como na música, o documentário mostra a difícil rotina enfrentada por alguns circenses e a potência do afeto que expressam pela prática que realizam.

Conforme mencionado por Bortoleto e Silva (2017), os "grupos familiares representaram e representam ainda uma das escolas do circo, uma das primeiras e mais consolidadas" (p. 109). Esses autores ressaltam a característica rizomática dos conhecimentos sobre o circo, de modo que, atualmente, coexistem diferentes sujeitos históricos e novas formas de expressão seja em academias, em projetos sociais, de forma autônoma ou na própria escola.

Ao refletirmos sobre o circo itinerante com o conjunto de estudantes, buscamos direcionar o olhar para uma importante realidade social, mas sem perder de vista a ideia de que ela não é estática. Isso porque, como antes mencionado, são diversas as formas de expressão e as potencialidades do circo, que vem ao longo do tempo, "ocupando as gretas, expandindo sua prática para um público cada vez mais abrangente, tratando de fomentar novas estratégias para a sua permanência na líquida e cambiante sociedade contemporânea” (ibidem, p. 108).

$\mathrm{Na}$ segunda semana, foi realizada a apresentação dos diferentes personagens do universo circense (malabaristas, globistas, palhaços, trapezistas, acrobatas, entre outros) e, então, foi realizada uma experimentação prática de algumas acrobacias de solo (começando com deslocamentos de diferentes formas, rolamentos até chegar à realização de pirâmides, bandeiras e algumas figuras acrobáticas).

\footnotetext{
${ }^{7}$ Disponível em: https://www.youtube.com/watch?v=ohk1HIfjpvo. Acesso em: 01 set. 2021.
} 
Fig. 3 - Fotos ilustrando algumas das experimentações realizadas:

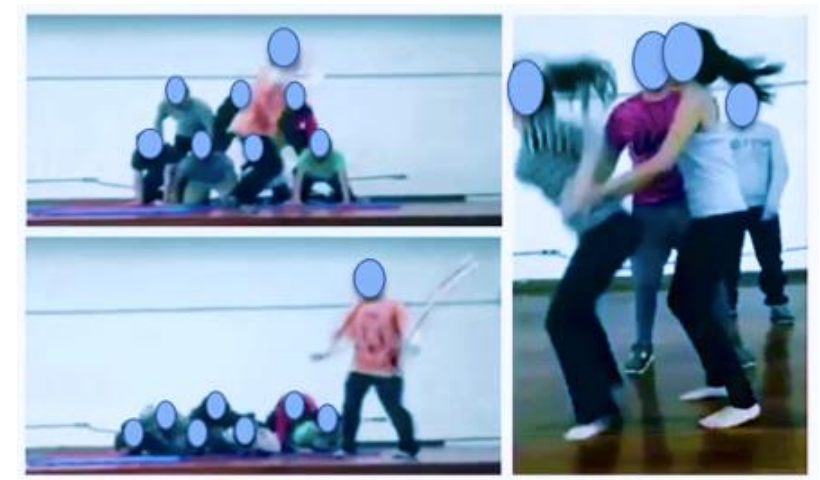

Fonte: Registro fotográfico dos autores.

Na semana seguinte, os malabares com bambolês e com bolas de diferentes tamanhos foram experienciados, tanto de forma individual quanto em grupo. De maneira contínua, os alunos e as alunas partilhavam suas impressões sobre as aulas e refletiam sobre os papéis ocupados por cada um nas atividades (CAMINHA; PAGÈS, 2017), de modo que ambos pudessem experienciar as funções de portô e volante, bem como explorar os malabares.

O espaço disponível para a realização das aulas práticas de Educação Física foi um pátio coberto sem quaisquer marcações de solo e buscou-se escolher as modalidades circenses mais apropriadas a ele, aos materiais, ao tempo de aula e ao interesse do alunado manifestado na roda de conversa da semana inicial.

A última semana de aula foi dividida entre a realização de jogos de mímica e improviso e um debate, em forma de roda de conversa, sobre o espetáculo e as dificuldades de ser artista de circo em uma sociedade altamente envolvida com as apresentações comerciais.

Conforme apontado por Debord (1997), na contemporaneidade, o espetáculo frequentemente objetifica o todo, de modo que as singularidades dos sujeitos são relegadas. A discussão realizada com os alunos e as alunas buscou gerar uma tomada de consciência crítica sobre algumas questões sociais e vai ao encontro do proposto por Neira (2020) e das ideias de Maldonado e Nogueira (2020), ao refletirem sobre a dimensão ético-política da prática pedagógica da Educação Física nesse ciclo de escolarização.

Com base nas rodas de conversa, nas pesquisas e na participação dos alunos e das alunas nas atividades práticas, consideramos, ao adotarmos a perspectiva de Larrosa $(2002 ; 2017)$, que o conjunto de discentes envolvidos nos processos educativos foram atravessados pelas experiências vividas deixando marcas em seus corpos.

Ao finalizar este projeto percebemos a potencialidade de que ele - somado a outros momentos formativos realizados ao longo do período escolar - leva a novas e diferentes "leituras de mundo" (FREIRE, 1992), possibilitando que os alunos e as alunas sejam capazes de se expressar 
corporalmente e se posicionar criticamente sobre diferentes questões durante a vida adulta fora da escola.

\section{Considerações Finais}

Iniciamos este trabalho com o intuito de relatar duas experiências exitosas com a utilização do circo como tema gerador em aulas de Educação Física escolar, acreditando que ultrapassaríamos a barreira do fazer por fazer, puramente motor, proporcionando aos alunos uma educação corporal artística e, consequentemente, estética.

Ao longo dos breves relatos, expusemos os planejamentos e os desdobramentos dos projetos realizados, sendo possível destacar que em nenhuma das propostas houve separação dos estudantes em grupos de meninos e meninas, inclusive nas acrobacias, nas quais muitas meninas desempenharam a função portô, indicando que, com o circo, foi possível trabalhar a equidade entre os gêneros, o que, muitas vezes, não acontece nas outras práticas corporais, como o esporte, por exemplo, que, de forma geral, vem se mostrando um espaço de demonstração de força e agressividade [...] e de "aspectos relacionados à masculinidade hegemônica" (MONTEIRO, 2016, p. 58) e que também podem ser desconstruídas a partir do debate e da reflexão crítica sobre os espaços ocupados por homens e mulheres na sociedade (SERRA PRAYERAS et al. 2020).

$\mathrm{O}$ acervo de saberes sobre o circo dos alunos e das alunas foi ampliado por meio do material apresentado, dos filmes ("O palhaço" e o documentário "Vida de circo"), com as imagens retiradas do livro o Circo Nerino, e com a letra da música do cantor Teixeirinha, o que se confirmou com as rodas de conversa, utilizadas para avaliar os projetos. Outra questão importante abordada no processo de compreensão do universo circense veio ao picadeiro quando os alunos começaram a discutir o processo histórico do circo itinerante, o cotidiano de uma família circense e também do universo artístico e estético do circo.

Gostaríamos de acrescentar que a pandemia causada pela SARS-CoV2, assim como em toda a educação nacional, prejudicou a execução do projeto na escola de Ensino Fundamental, que tinha no seu planejamento a intenção de ampliar as modalidades circenses, indo além das acrobacias. Também se faz necessário acrescentar que existem outras modalidades oriundas desse universo que são passíveis de serem ensinadas na escola, cabendo aos docentes a ousadia de explorá-las.

No Ensino Médio, a possibilidade de discutir uma dimensão sociocultural mais ampla do cotidiano de uma família circense estabelece um estreito diálogo com uma formação humanizadora, 
atenta às disparidades sociais e em uma perspectiva crítica, fundamentais para esse ciclo de escolarização.

Ressaltamos, por fim, que experiências como as aqui apresentadas são essenciais para a consolidação do circo na escola, quer seja na Educação Física, nas Artes ou em projetos interdisciplinares, explorando as potencialidades estéticas, artísticas, afetivas, críticas e socioculturais desse patrimônio cultural da humanidade.

\section{REFERÊNCIAS}

APPLE, Michael. Poder, significado e identidade: ensaio de estudos educacionais críticos. Porto: Porto Editora, 1999.

BAUMAN, Zygmunt. O mal-estar da pós-modernidade. Rio de Janeiro: Zahar, 1998.

BERGMANN, Jonathan; SAMS, Aaron. Sala de aula invertida: uma metodologia ativa de aprendizagem. Rio de Janeiro: LTC, 2017.

BOLOGNESI, Mario Fernando. Palhaços. São Paulo: Editora UNESP, 2003.

BONETTO, Pedro Xavier Russo; NEIRA, Marcos Garcia. Multiculturalismo: polissemia e perspectivas na Educação e Educação Física. Dialogia, v. 1, p. 69-82, 2017. Disponível em:

https://periodicos.uninove.br/dialogia/article/view/6624 Acesso em: 01 set. 2021.

BORTOLETO, Marco Antonio Coelho (Org.). Introdução à pedagogia das atividades circenses. Jundiaí: Editora Fontoura, 2008.

BORTOLETO, Marco Antonio Coelho (Org.). Introdução à pedagogia das atividades circenses. Jundiaí: Editora Fontoura, v. 2, 2010.

BORTOLETO, Marco Antonio Coelho; SILVA, Erminia. Circo: Educando entre as gretas. Rascunhos, v. 4, n. 2, 104-117, 2017. Disponível em: https://doi.org/10.14393/issn2353-3703.v4n2a2017-07 Acesso em: 08 dez. 2021.

BORTOLETO, Marco Antonio Coelho; MACHADO, Gustavo Arruda. Reflexões sobre o circo e a Educação Física. Corpoconsciência, Santo André, SP, n. 12, p. 39-69, 2003. Disponível em:

https://periodicoscientificos.ufmt.br/ojs/index.php/corpoconsciencia/article/view/3923 Acesso em: 01 set. 2021.

BRASIL. Parâmetros Curriculares Nacionais: introdução aos parâmetros curriculares nacionais / Secretaria de Educação Fundamental. Brasília: MEC/SEF, 1997. Disponível em: http://portal.mec.gov.br/seb/arquivos/pdf/introducao.pdf Acesso em: 01 set. 2021.

BRASIL. Base Nacional Comum Curricular. Brasília: MEC, 2017. Disponível em: http://portal.mec.gov.br/conselho-nacional-de-educacao/base-nacional-comum-curricular-bncc Acesso em: 01 set. 2021.

CAMINHA, Melissa Lima; PAGÈS, Judit Vidiella. Payasas mujeres y mujeres payaso: el travestismo en la payasaria. Visualidades, v. 15, n. 1, p. 143-170, 2017. Disponível em:

https://www.revistas.ufg.br/VISUAL/article/view/48278 Acesso em: 08 dez. 2021. 
CANDAU, Vera Maria (Org.). Didática crítica intercultural: aproximações. Petrópolis: Vozes, 2012.

CARRASCO-SEGOVIA, Sara; HERNÁNDEZ-HERNÁNDEZ, Fernando. Cartografiar los afectos y los movimientos en el aprender corporeizado de los docentes. Movimento, Porto Alegre, v. 26, e26012, 2020. Disponível em: https://doi.org/10.22456/1982-8918.94792 Acesso em 01 set. 2021.

CONTRERAS, José. Relatos de experiencia, en busca de un saber pedagógico. Revista Brasileira de Pesquisa (Auto) Biográfica, v. 1, n. 1, p. 14-30, 2016. Disponível em:

https://www.revistas.uneb.br/index.php/rbpab/article/view/2518 Acesso em: 01 set. 2021.

DEBORD, Guy. A sociedade do espetáculo. Trad. Estela dos Santos Abreu. Rio de Janeiro: Editora Contraponto, 1997.

DELEUZE, Gilles; GUATTARI, Felix. O que é a filosofia: capitalismo e esquizofrenia 2. Rio de Janeiro: Editora 34, 2011. v. 1.

DUPRAT, Rodrigo Mallet; PÉREZ-GALLARDO, Jorge Sergio. Artes circenses no âmbito escolar. Ijuí: Unijuí, 2010.

DUPRAT, Rodrigo Mallet; BORTOLETO, Marco Antonio Coelho. Educação Física escolar: pedagogia e didática das atividades circenses. Revista Brasileira de Ciências do Esporte, v. 28, p. 171-189, 2007. Disponível em: http://revista.cbce.org.br/index.php/RBCE/article/view/63 Acesso em: 01 set. 2021.

FERRACINI, Renato. As setas longas do palhaço. Revista Sala Preta, n. 6, p. 65-69, São Paulo, 2006.

FOUCAULT, Michel. Vigiar e punir. Trad. Lígia Vassalo. Petrópolis: Vozes, 1977.

FREIRE, Paulo. Educação como prática da liberdade. Rio de Janeiro: Paz e Terra, 1967.

FREIRE, Paulo. A importância do ato de ler: em três artigos que se complementam. 27. ed. São Paulo: Paz e Terra, 1992.

FREIRE, Paulo; SHOR, Ira. Medo e ousadia: cotidiano do professor. Rio de Janeiro: Paz e Terra, 1986.

GADAMER, Hans-George. Verdade e método I: traços fundamentais de uma hermenêutica filosófica. 15 ed. Petrópolis: Editora Vozes, 2015.

GATTI, Bernadete Angelina; BARRETO, Elba Siqueira de Sá; ANDRÉ, Marli Eliza Dalmazo Afonso de; ALMEIDA, Patrícia Cristina Albieri de. Professores do Brasil: novos cenários de formação. Brasília: UNESCO, 2019.

GENTILI, Pablo. Que há de novo nas novas formas de exclusão educativa? Neoliberalismo, trabalho e educação. Educação e Realidade, v. 20, n. 1, p. 191-202, jan./jun. 1995.

Disponível em: https://seer.ufrgs.br/educacaoerealidade/article/view/71754 Acesso em: 01 set. 2021.

GODOY, Luís Bruno de; JUNIOR, Roberto Donato da Silva; SCHULZ, Peter Alexander Bleinroth. O palhaço no espaço do vazio no contexto hospitalar: a incerteza como potência criadora. Repertório, v. 1, n. 35, 2021. Disponível em: https://doi.org/10.9771/r.v1i35.31964. Acesso em: 01 set. 2021.

INEP. Instituto Nacional de Estudos e Pesquisas Educacionais Anísio Teixeira. Sinopse Estatística da Educação Básica. Brasília: INEP, 2019.

Disponível em: https://www.gov.br/inep/pt-br/acesso-a-informacao/dados-abertos/sinopses-

estatisticas/educacao-basica Acesso em: 01 set. 2021. 
LAERTE. Suriá, a garota do circo. São Paulo: Devir/Jacarandá, 2000.

LARROSA, Jorge. Notas sobre a experiência e o saber da experiência. Revista Brasileira de Educação, Rio de Janeiro, n. 19, p. 20-28, abr. 2002. Disponível em: https://doi.org/10.1590/S1413-24782002000100003 Acesso em: 01 set. 2021.

LARROSA, Jorge. Tremores: escritos sobre a experiência. Belo Horizonte: Editora Autêntica, 2017.

MALDONADO, Daniel Teixeira; NOGUEIRA, Valdilene Aline. Educação física no ensino médio: experiências educativas inspiradas pelos ensinamentos freireanos. Caderno de Educação Física e Esporte, Marechal Cândido Rondon, v. 18, n. 1, p. 49-54, fev. 2020. Disponível em: https://doi.org/10.36453/23185104.2020.v18.n1.p49 Acesso em: 01 set. 2021.

MELO, Caroline Capellato; BORTOLETO, Marco Antonio Coelho; BARRAGÁN, Teresa Ontañón. Risas, brincos y volteretas: la enseñanza del circo en la escuela como actividad extracurricular. Retos, 42, 897-906. 2021. Disponível em: https://doi.org/10.47197/retos.v42i0.86337 Acesso em: 01 set. 2021.

MONTEIRO, Marcos Vinicius Pereira. Gênero e naturalização das diferenças na Educação Física escolar. Temas em Educação Física Escolar, Rio de Janeiro, v. 1, n. 1, p. 53-71, 2016. Disponível em: http://dx.doi.org/10.33025/tefe.v1i1.637 Acesso em: 01 set. 2021.

NEIRA, Marcos Garcia. O multiculturalismo crítico e suas contribuições para o currículo da Educação Física. Temas em Educação Física Escolar, Rio de Janeiro, v. 1, n. 1, p. 3-29, jan.-jun. 2016. Disponível em: http://dx.doi.org/10.33025/tefe.v1i1.628 Acesso em: 01 set. 2021.

NEIRA, Marcos Garcia. Os conteúdos no currículo cultural da educação física e a valorização das diferenças: análises da prática pedagógica. Revista e-Curriculum, São Paulo, v. 18, n. 2, p. 827-846, abr./jun., 2020. Disponível em: https://dialnet.unirioja.es/servlet/articulo?codigo=7843385 Acesso em: 01 set. 2021.

NOVAES, Adauto. O homem-máquina: a ciência manipula o corpo. São Paulo: Companhia das Letras, 2003.

OLIVEIRA, Fernando Dias de; MALDONADO, Daniel Teixeira. Educação Física Escolar no Ensino Médio: estímulo ao pensamento crítico e à formação da cidadania dos estudantes. In: MALDONADO, Daniel Teixeira; NOGUEIRA, Valdilene Aline; FARIAS, Uirá Siqueira. Os professores como intelectuais: novas perspectivas didático-pedagógicas na Educação Física Escolar brasileira. Curitiba: CRV, 2018. p. 265-280.

OLIVEIRA, Fernando Dias de; PESCE, Lucila. A formação docente, as tecnologias digitais da informação e comunicação e a inclusão digital nas escolas públicas: entre avanços e contradições. In: PESCE, Lucila. (Org.). Inclusão digital e empoderamento freireano: a formação de professores da educação básica em uma perspectiva dialógica e autoral. Uberlândia: Navegando Publicações, 2020. p. 107-119.

ONTAÑÓN, Teresa Barragán. Circo na escola: por uma educação corporal, estética e artística. 2016. Tese (Doutorado), Faculdade de Educação Física, Universidade Estadual de Campinas, Brasil, 2016.

PARNET, Claire. O abecedário de Gilles Deleuze. Site Dossiê Gilles Deleuze. 2010.

RIBEIRO, Camila da Silva; CARDANI, Leonora Tanasovici; RODRIGUES, Gilson Santos; BORTOLETO, Marco Antonio Coelho. O "não lugar" do circo na escola. Revista Portuguesa de Educação, v. 34, n.1. p. 246-263, 2021. Disponível em: https://revistas.rcaap.pt/rpe/article/view/16128 Acesso em 01 set. 2021.

SAVIANI, Demerval. História das idéias pedagógicas no Brasil. Campinas: Autores Associados, 2007. 
SERRA PRAYERAS, Pedrona; PRAT GRAU, Maria; NICOLINO, Aline da Silva; SOLER PRAT, Susanna; SILVA, Ana Márcia. Género y currículum de formación del profesorado en Educación Física: un diálogo entre Brasil y España. Revista Iberoamericana De Educación, v. 82, n. 2, p. 191-210, 2020. Disponível em: https://doi.org/10.35362/rie8223637 Acesso em: 01 set. 2021.

SOARES, Carmen Lúcia. Imagens da educação no corpo: estudo a partir da ginástica francesa no século XIX. Campinas: Autores Associados, $4^{\circ}$ ed., 2013.

ZAIM-DE-MELO, Rogerio; RIZZO, Deyivid Tenner de Souza; GODOY, Luis Bruno de; AMARAL, Laurianne Sorilla do. A utilização do tecido acrobático como conteúdo nas aulas de educação física escolar: um estudo com uma nona série do ensino fundamental. Repertório, Salvador, ano 23, n. 35, p. 63-86, 2020. Disponível em: https://periodicos.ufba.br/index.php/revteatro/article/view/35454 Acesso em 01 set. 2021.

ZAIM-DE-MELO, Rogerio; GODOY, Luis Bruno de; BRACCIALLI, Felipe. Quando o nariz vermelho se encontra com a Educação Física: potencialidades do palhaço como conteúdo na escola. Motrivivência, Florianópolis, v. 32, n. 63, p. 01-20, 2020. Disponível em: https://doi.org/10.5007/2175-8042.2020e76909 Acesso em 01 set. 2021.

\section{NOTAS DE AUTOR}

AGRADECIMENTOS - Não se aplica.

CONTRIBUIÇÃO DE AUTORIA - Não se aplica.

FINANCIAMENTO - Não se aplica.

CONSENTIMENTO DE USO DE IMAGEM - Não se aplica.

APROVAÇÃO DE COMITÊ DE ÉTICA EM PESQUISA - Não se aplica.

CONFLITO DE INTERESSES - Não se aplica.

\section{LICENÇA DE USO}

Os autores cedem à Motrivivência - ISSN 2175-8042 os direitos exclusivos de primeira publicação, com o trabalho simultaneamente licenciado sob a Licença Creative Commons Attribution Non-Comercial ShareAlike (CC BY-NC SA) 4.0 International. Esta licença permite que terceiros remixem, adaptem e criem a partir do trabalho publicado, desde que para fins não comerciais, atribuindo o devido crédito de autoria e publicação inicial neste periódico desde que adotem a mesma licença, compartilhar igual. Os autores têm autorização para assumir contratos adicionais separadamente, para distribuição não exclusiva da versão do trabalho publicada neste periódico (ex.: publicar em repositório institucional, em site pessoal, publicar uma tradução, ou como capítulo de livro), com reconhecimento de autoria e publicação inicial neste periódico, desde que para fins não comerciais e compartilhar com a mesma licença.

\section{PUBLISHER}

Universidade Federal de Santa Catarina. Programa de Pós-Graduação em Educação Física. LaboMídia - Laboratório e Observatório da Mídia Esportiva. Publicado no Portal de Periódicos UFSC. As ideias expressadas neste artigo são de responsabilidade de seus autores, não representando, necessariamente, a opinião dos editores ou da universidade. 


\section{EDITORES}

Mauricio Roberto da Silva, Giovani De Lorenzi Pires, Rogério Santos Pereira.

\section{EDITOR DE SEÇÃO}

Silvan Menezes dos Santos

\section{REVISÃO DO MANUSCRITO E METADADOS}

Juliana Rosario; Keli Barreto Santos.

\section{HISTÓRICO}

Recebido em: 02 de setembro de 2021.

Aprovado em: 26 de janeiro de 2022. 